\title{
Study of Synchronous Generator Parameters Test and the Method of Identification
}

\author{
WANG Xiao-ming, ZHOU Wei \\ Electric Power Research Institute of GUANGXI Power Grid Co., Ltd, Nanning, China \\ Email: wang_xm.sy@gx.csg.cn
}

Keywords: Synchronous generator, load rejection method, Graphical method, Parameters identification, PSD-BPA

\begin{abstract}
The precise generator parameters can provide some necessary data support for the stability analysis and safe operation, in order to further improve the level of the safe and stable operation of power system, the generator parameters measurement and identification is particularly important. The load rejection method is a practical way for measuring generator parameters, it is one of the most common method by using the graphical method or curve fitting method to identify the parameters of the generator, but the graphical method is greatly influenced by load rejection process of interference, the identification parameters is not accurate. To improve effectively the identification accuracy of parameters, a method of identification synchronous generator parameters based on load rejection test and the PSD-BPA simulation is raised, the experimental data of direct axis and quadrature axis are acquired by load rejection test, then the simulation model is established and it is the same as the load rejection test actually, the generator parameters are identifying by simulation result compared with the field test results, this method considers the field current changes in the process of load rejection and overcome the deficiency of the graphical method, it has improved the accuracy effective of the parameters identification .
\end{abstract}

\section{Introduction}

With the growing of electrical power system capacity and scale, the problem of the safe and stable operation for power system is prominent increasingly, it puts forward higher request for the analysis and off-line simulation of power system, because it want to guide the adjustment of the whole power system operation mode by the simulation calculation results, the reasonable component of power system model and its accurate parameters on the accuracy of simulation calculation for power system has a great influence. Currently in the process of actual simulation calculation, such as generator parameters are selecting some typical data in the manual, this data is not considers the foucault current, saturation and the material aging during the operation of generator compared with actual operation parameters, the typical data may have a bigger difference with the actual operation parameters, it will directly affect the simulation calculation results. So the generator parameters measurement and parameter identification is particularly important and load rejection method has been widely used (Wamkeue R\&Kamwa I,2006 and Wamkeue R\&Baetscher F ,2008 and Wamkeue R\& Jolette C ,2010 ). 
It is one of the most common method by using the graphical method or curve fitting method to identify the parameters of the generator, but the accurate graphical method was applied to select feature points are difficult, and greatly influenced by interference in the process of load rejection test, such as changes of exciting current in the process of load rejection test, etc[4-8]. In order to further enhance the accuracy of load rejection method, it is used to identify the generator parameters, this paper proposes a method that is used to transient stability based on PSD - BPA program simulation and load rejection test. This method considers the field current changes in the process of load rejection and overcome the deficiency of the graphical method, it has improved the accuracy effective of the parameters identification, it provides a more precise analysis parameters for power system.

\section{Transition process of load rejection}

If it neglect the rotating speed change, the transformer voltage and the stator resistance, the stator current is zero after load rejection test, the basic equation of synchronous generator can be simplified as follows.

$$
\begin{aligned}
& u_{d}=x_{a q} i_{Q} \\
& u_{q}=x_{a d} i_{f}+x_{a d} i_{D}
\end{aligned}
$$

where $u_{d}$ is direct axis voltage, $u_{q}$ is quadrature axis voltage, $x_{a d}$ is direct axis armature reaction reactance, $x_{a q}$ is quadrature axis armature reaction reactance, $i_{f}$ is rotor current, $i_{D}$ is direct axis damping current, $i_{Q}$ is quadrature axis damping current.

It will motivates free current in the stator and the damping winding When the stator current is interrupted suddenly in the process of load rejection test, and the free current will be attenuated according to the certain time constant . According to the rotor current and the direct axis, quadrature axis damping current variation after load rejection, we note that the basic equation of load rejection is in the form

$$
\begin{aligned}
& u_{d}=E_{d 0} " e^{-t / T_{q 0} "} \\
& u_{q}=E_{q 0}+\left(E_{q 0}{ }^{\prime}-E_{q 0}\right) e^{-t / T_{d 0}} \\
& +\left(E_{q 0}^{\prime \prime}-E_{q 0}{ }^{\prime}\right) e^{-t / T_{d 0} \prime}
\end{aligned}
$$

Where $E_{q 0}$ is quadrature axis electromotive force, $E_{q 0}$ 'is quadrature axis transient electromotive force, $E_{q 0}$ " is quadrature axis sub-transient electromotive force, $T_{d 0}$ ' is time constant of rotor winding,$T_{d 0}$ "is transient open circuit time constant, $T_{q 0}$ "is quadrature axis sub-transient time constant, $E_{d 0} 0^{\prime}$ is direct axis sub-transient electromotive force.

\section{Load rejection test and parameters identification}

\subsection{Load rejection test}

According to the mentioned above, the generator has only the direct axis magnetic flux when carrying out the direct axis load rejection testing, there the generator can only send reactive power, in the process of load rejection $I q=0, I_{0}=I_{d 0}$, the measured voltage of the machine for $U q$, the vector diagram shown in Figure 1. 


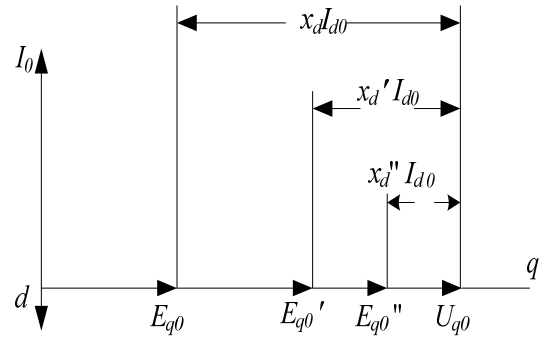

Figure1.The direct axis load rejection vector diagram

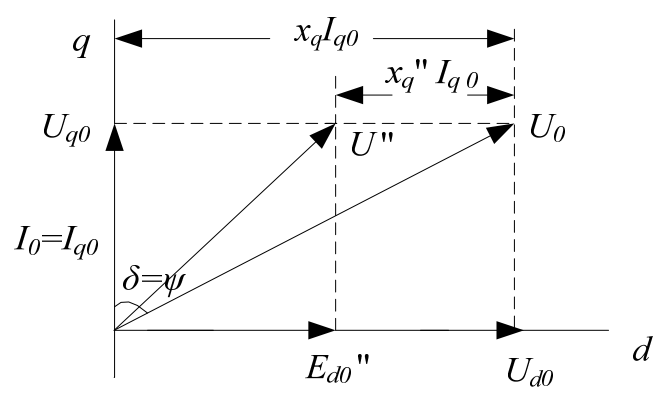

Figure 2 The quadrature axis load rejection vector diagram

Where $U q 0$ is steady-state voltage before load rejection, $E q 0$ is steady-state voltage after load rejection, $I d O$ is stator current before load rejection.

Similarly, the generator has only the quadrature axis magnetic flux when carrying out the quadrature axis load rejection testing,we must establish a stable condition, that has to make $I_{d}=0$, $I_{0}=I q 0$, the vector diagram as shown in Figure 2, where the power angle and power factor angle is now equal, where $U_{0}$ is the steady state voltage before the load rejection, $I_{q 0}$ is the steady current before load rejection, the $U_{q 0}$ is the steady voltage after load rejection, and the $U$ " is the subtransient voltage which does not change in the transient process.

In this paper, the direct and quadrature axis load rejection testing is carried out for a unit of a hydropower plant, in order to identify the parameters of the direct axis and quadrature axis of the generator. The generator capacity is $160.5 \mathrm{MVA}$, the power is $139 \mathrm{MW}$, the power factor is 0.85 , the rated voltage is $15.75 \mathrm{kV}$, the stator current is $5854 \mathrm{~A}$, the speed is $108 \mathrm{r} / \mathrm{min}$. The excitation system of the generator adopts a static silicon controlled excitation mode which is supplied by the excitation transformer connected to the generator end.

According to the foregoing, the direct axis load rejection test needs to be carried out only under the condition of reactive power and zero active power, and the quadrature axis load rejection test needs to be carried out under this condition that the power angle and power factor angle is equal. it can also run for leading phase or lagging phase operation, in order to ensure the safety of operation, in general the load rejection test choose the condition of leading phase, because under the condition of lagging phase the terminal voltage will rise, while the lagging phase condition will be reduced. However, it is necessary to understand the generator's operation ability before the test. The test results are shown in Figure 3, Figure 4.
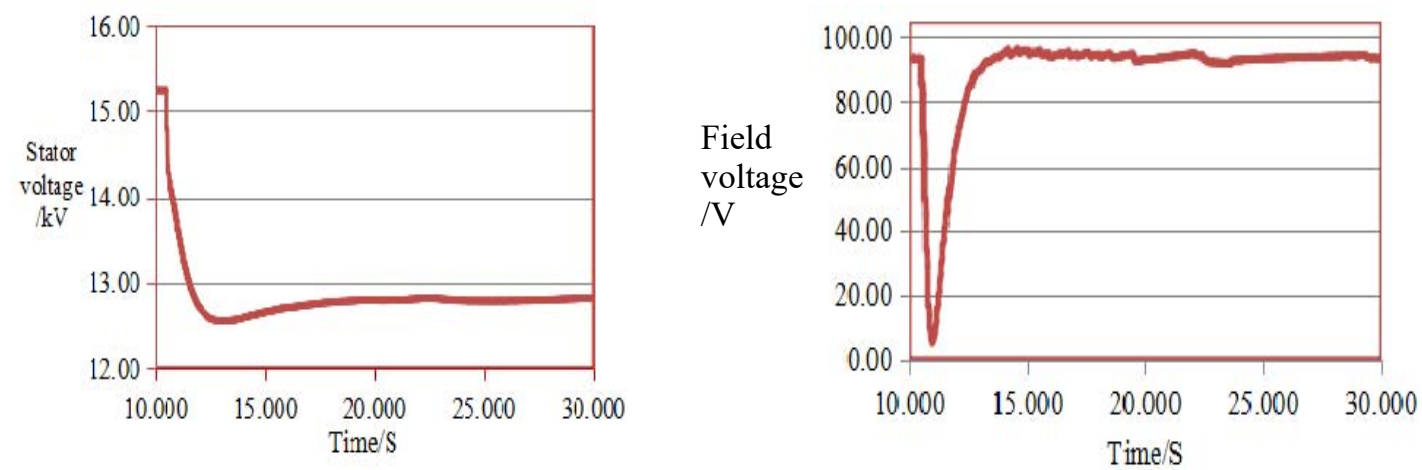

Figure 3.The test waveform of direct axis load rejection 

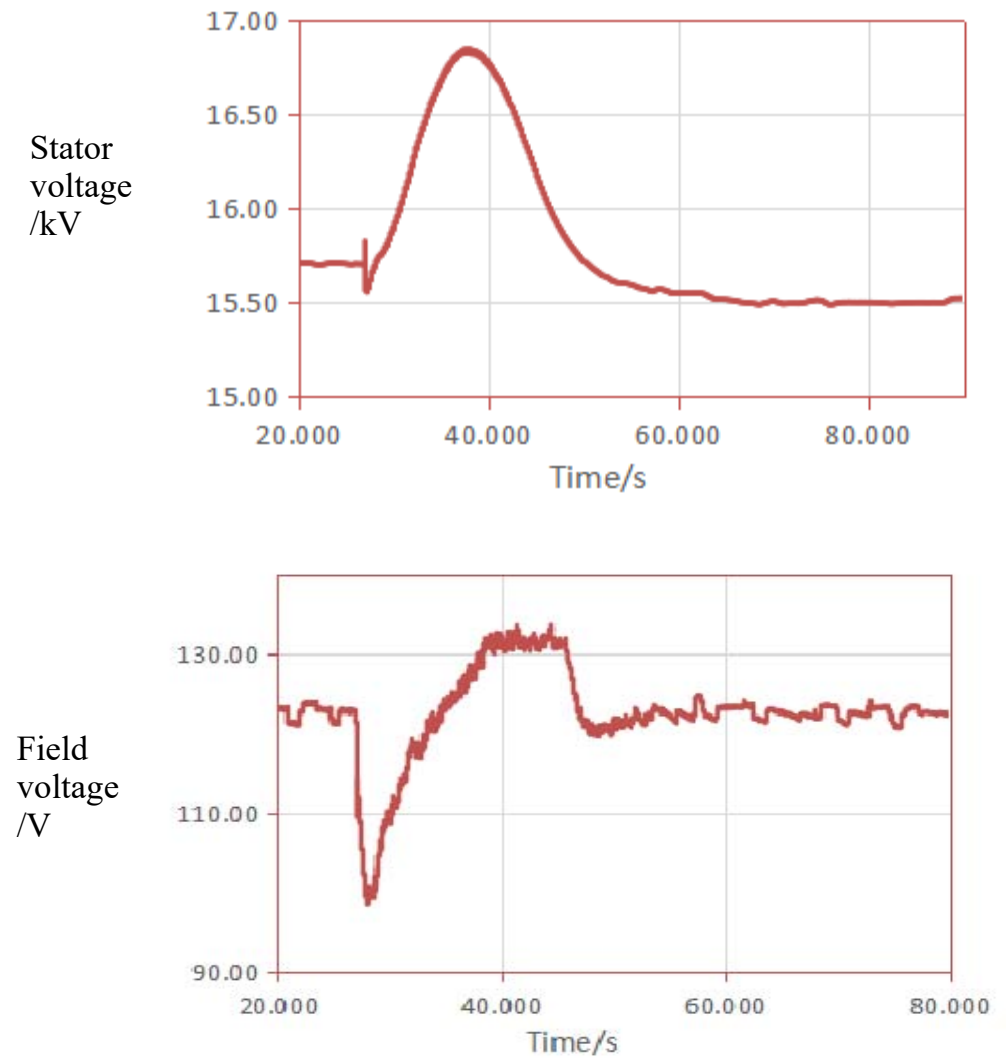

Figure 4.The test waveform of quadrature axis load rejection

\subsection{Parameters identification}

The traditional method of parameters identification based on load rejection test is graphic method (CHENG Zhong-yun, 1994 and LI Xiao-xia, 2007). Because the load rejection actually is not ideal, when we are using graphic method for identifying parameters of generator, due to the field current changes in load rejection, the stator voltage waveform is not completely decay curve, the decay process of stator voltage will be affected by the varying field current. So, the graphic method for identifying parameters is not accurate.

The method of combining the PSD-BPA simulation and the load rejection test can identify the generator parameters accurately, because the simulation model established by PSD-BPA is the same as the field load rejection test. In addition, the field test for no-load characteristics is carried out, in order to determine the saturation characteristics of the generator, and then to obtain the saturation coefficient of the PSD-BPA simulation.

\subsubsection{Simulation model by PSD-BPA}

The single-machine infinite-bus system model is established by using the power flow program of PSD-BPA, and then the simulation model is established by using the stable program, which is same as actual operating mode. Taking the direct axis load simulation model for example, the power flow program of PSD-BPA uses the BS card to define the equivalent node of the infinite system, the B card defines the PQ node, the L card defines the line data, and fill in the corresponding card content according to the actual working condition.

In the stable program of PSD-BPA, the MC card defines the infinite system, M and MF Card defines the basic parameter of generator. In particular, the excitation system model should use the 
$E^{*}$ card, $E^{*}$ card is different from the traditional excitation model which allow to import the field voltage. Because in the actual load rejection test, the field regulator is a manual control mode, the excitation voltage will not change theoretically, but the test from Figure 3, Figure 4 shows that the field voltage changes in the load rejection process. In order to make the simulation model consistent with the actual, we need to import the field voltage into the simulation model. In addition, the LB card is used to define the load model, and the LS card is used for load shedding operation. And then we will fill in the corresponding card content according to the actual working conditions.

\subsubsection{Parameters identification by PSD-BPA}

Then we are carrying out the simulation of direct and quadrature axis load rejection by using the PSD-BPA simulation model, which should be paid attention to identify the quadrature axis parameters, we should take into account the speed changes, because the generator with active power when it carried out the quadrature axis load rejection, the generator speed increases. The highest frequency is $55 \mathrm{~Hz}$, in order to simplify the simulation model, the stator voltage is adjusted to the rated frequency, adjusted as shown in Figure 5, then the parameter identification are carried out.

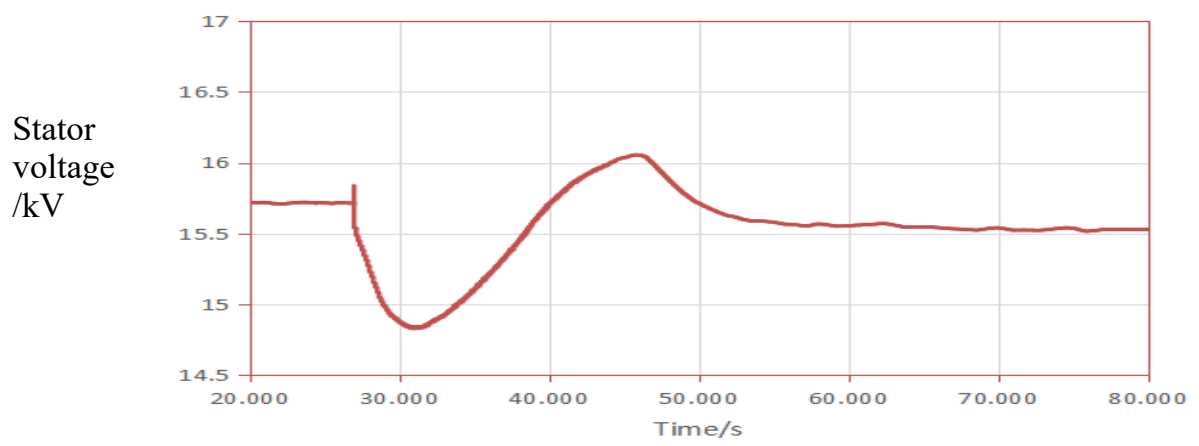

Figure 5. The revised waveform of stator voltage after quadrature axis load rejection

The method of using the simulation to identify the parameters is to adjust the parameters of the direct and quadrature axis of the generator step by step.

For the direct axis parameter identification example, we should adjust the $x_{d}$ to make the simulation curve to stay in step with the experimental curve of stator voltage in steady state, then adjust the $x_{d^{\prime}}$ and $T_{d 0^{\prime}}$ to make the simulation curve to stay in step with the experimental curve of stator voltage in the transient stage, and then adjust the $x_{d}$ ", $T_{d 0}$ to make the simulation curve to stay in step with the experimental curve of stator voltage in sub-transient state. Finally, the direct axis parameters of generator are identified. The direct axis identification parameters simulation, the original parameters simulation and test of the stator voltage curve shown in Figure 6. 


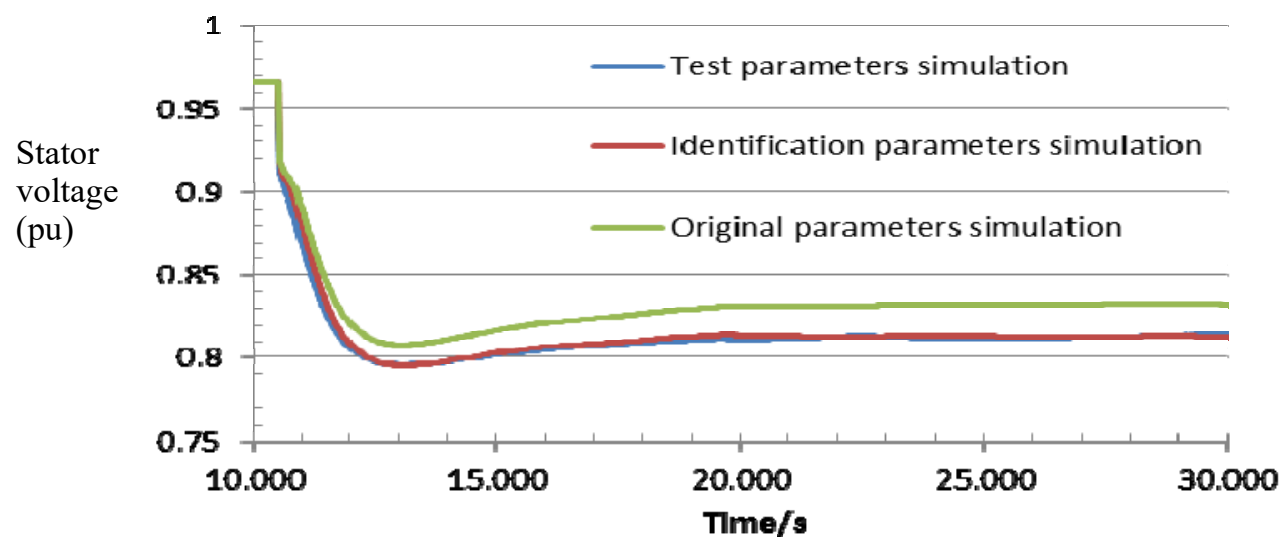

Figure 6.The direct axis load rejection test data and simulation waveform

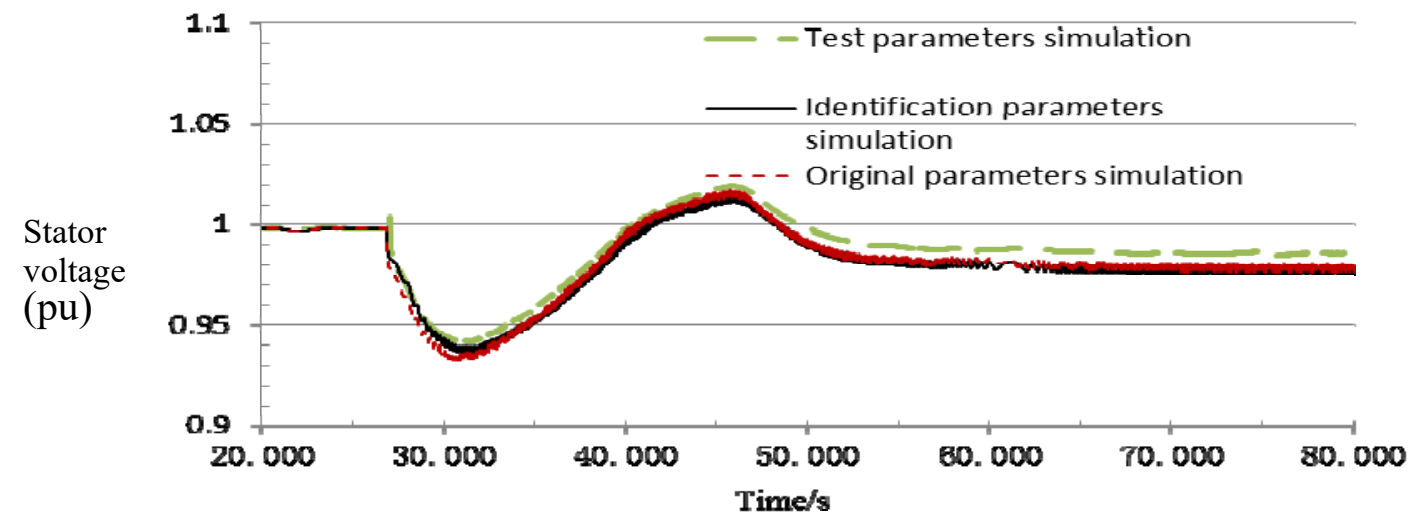

Figure 7.The quadrature axis load rejection test data and simulation waveform

Similarly, for the quadrature axis parameters identification method as mentioned above, the simulation curve and the measured stator voltage curve can be obtained as shown in Figure 7.

The simulation results of identification parameters more close to the measured than the original parameters of the simulation results from the figure 6 and 7 .And the accuracy of the identification parameters are validated by the simulation. The identification parameters by using PSD-BPA simulation shown in the following table.

Table 1 Identification and Original parameters

\begin{tabular}{|c|c|c|}
\hline Generator parameters & Identification parameters & Original parameters \\
\hline$x_{d}$ & 1.12 & 1.03 \\
\hline$x_{d}^{\prime}$ & 0.358 & 0.365 \\
\hline$x_{d}^{\prime \prime}$ & 0.29 & 0.32 \\
\hline$T_{d 0^{\prime}}$ & 7.08 & 6.87 \\
\hline$T_{d 0}{ }^{\prime \prime}$ & 0.05 & 0.131 \\
\hline$x_{q}$ & 0.75 & 0.735 \\
\hline$x_{q}^{\prime}$ & 0.75 & 0.735 \\
\hline$x_{q}^{\prime \prime}$ & 0.281 & 0.291 \\
\hline$T_{q 0^{\prime}}$ & 0.07 & 0.07 \\
\hline$T_{q 0}{ }^{\prime \prime}$ & 0.132 & 0.132 \\
\hline
\end{tabular}




\section{Conclusion}

The load rejection method is a practical way for measuring generator parameters, which is in the actual operation conditions. The measured parameters is accurate, because it considers the effects of saturation. The graphical method of identification parameters is not accurate, in order to improve effectively the identification accuracy of parameters, a method of identification synchronous generator parameters based on load rejection test and the PSD-BPA simulation is raised. The simulation model is established and it is the same as the load rejection test actually and then we can identify all the parameters step by step. This method considers the field current changes in the process of load rejection, the identification parameters have more tally with the actual situation and higher precision.

\section{References}

[1] Wamkeue R, Kamwa I, Baetscher, et al. A new and efficient approach for analysis of a saturated synchronous generator under the load rejection test[J]. Electric Power Components and Systems, 2006, 34(5):539-563.

[2] Wamkeue R, Jolette C, Kairous D. Estimation of synchronous generator parameters form load rejection analytical responses[C]. $20109^{\text {th }}$ International Conference on Environment and Electrical Engineering, Prague, Czech Republic, IEEE, 2010:392-395.

[3] Wamkeue R, Baetscher F, Kamwa I. Hybrid-state-moder-based time-domain identification of synchronous machine parameters from saturated load rejection test records[J]. IEEE Transacions on Energy Conversion, 2008, 23(1):68-77.

[4] CHENG Zhong-yun. Application of the $\mathrm{d} / \mathrm{q}$ axis load rejection method to measuring parameters of synchronous electric machine[J]. Large Electric Machine and Hydraulic Turbine, 1994, 6(1):32-35.

[5] LI Xiao-xia, ZHANG Yan, GUO Lei, Measuring parameters of hydro-generator by using load rejection method[J]. Shanxi Electric Power, 2007,35(8):42-44. 